\title{
Repair of complete atrioventricular septal defect with tetralogy of Fallot
}

\author{
Edvin Prifti \\ Division of Cardiac Surgery, University Hospital Center of Tirana, Albania \\ Correspondence to: Edvin Prifti, MD, PhD. Division of Cardiac Surgery, University Hospital Centre of Tirana "Mother Teresa", Tirana, Albania. \\ Email: edvinprifti@hotmail.com. \\ Provenance: This is a Guest Editorial commissioned by the Section Editor Xicheng Deng (Department of Cardiothoracic Surgery, Hunan Children's \\ Hospital, Changsha, China). \\ Comment on: Vitanova K, Cleuziou J, Schreiber C, et al. Long-Term Outcome of Patients With Complete Atrioventricular Septal Defect Combined \\ With the Tetralogy of Fallot: Staged Repair Is Not Inferior to Primary Repair. Ann Thorac Surg 2016. [Epub ahead of print].
}

Submitted Nov 29, 2016. Accepted for publication Nov 30, 2016.

doi: $10.21037 /$ tp.2017.01.01

View this article at: http://dx.doi.org/10.21037/tp.2017.01.01

The association of the tetralogy of Fallot (TOF) with a complete atrioventricular septal defect (CAVSD) is a wellrecognized congenital heart malformation occurring in $5-10 \%$ of hearts with CAVSD and in $1.7 \%$ of patients with TOF (1). The complex exhibits features of CAVSD and TOF, specifically a nonrestrictive inlet-type ventricular septal defect (VSD) with anterior extension, an ostium primum, a common unpartitioned atrioventricular valve, anterosuperior deviation of the infundibular septum, and right ventricular outflow tract obstruction (RVOTO) (1). CAVSD associated with TOF (CAVSD-TOF) affects the septa of both atria and ventricles and both ventricular inlets and outlets. Initial experiences of surgical correction for this lesion were associated with high mortality (2-4), however recent reports have demonstrated acceptable outcome (5-14). Controversy still exists about the surgical approach, this related to the number of patches employed for CAVSD correction, the use of a right ventriculotomy, cleft closure and RVOT reconstruction, employment of a transannular patch, previous palliative procedures etc $(15,16)$. The timing of complete repair and the utility of a preliminary shunt have not been well defined in the literature yet.

\section{Palliative procedures}

Preoperative palliation procedures consist in a systemic-topulmonary shunt. The primary indication for palliation is cyanosis. The decision to undergo palliation is based on a series of factors, including age at presentation, severity of symptoms and surgeon preference.

\section{CAVSD repair}

In our experience we employed the classic onepatch technique and two patch technique as described previously (17). In some cases we employed the modified one-patch technique (Figure 1) as described previously (18). Maximal tissue should be preserved for left atrioventricular valve (LAVV) reconstruction by making these incisions along the right ventricular aspect of the ventricular septal crest. The margins of the VSD should be clearly visualized and identified. In cases when one-patch technique are employed than four everting pericardial pledget stitches (Polypropylene 5/0) are placed at the coaptation site of each of the newly created atrioventricular valve leaflets and then fixed under tension to provide a better exposure of the VSD (Figure 1A). The pericardial patch should be tailored to the VSD dimensions with redundancy anteriorly. The patch is sewn along the ridge of the muscular septum. Closure of the anterosuperior extension of the VSD is aided by exposure through the right ventricular incision if necessary. In these cases, the suture is withdrawn through the ventriculotomy and the patch is sewn around the aortic root. When the annulus is reached posteriorly, the suture line is carried toward the left ventricle to avoid injuring the atrioventricular node. The atrial component is closed 


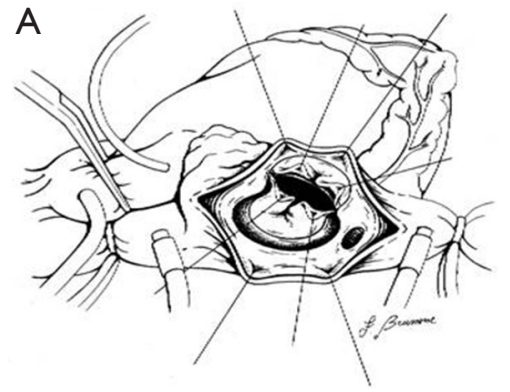

C

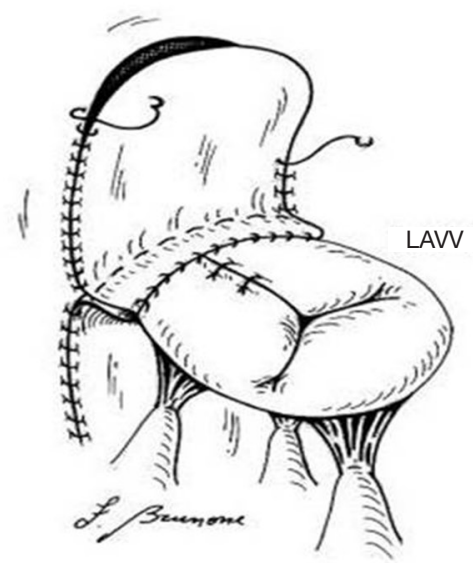

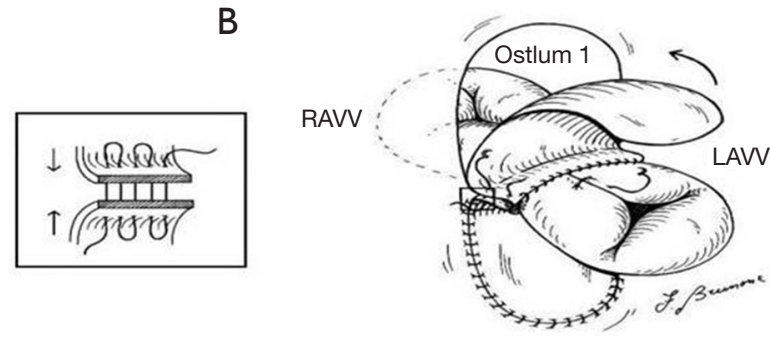

D

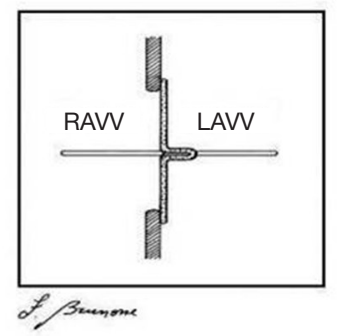

Figure 1 Modified single-patch technique for complete atrioventricular septal defect. (A) Four everting pericardial pledget stitches (Polypropylene 5/0) are placed at the coaptation site of each of the newly created atrioventricular valve leaflets and then fixed under tension to provide a better exposure of the ventricular septal defect; (B) the patch plication towards the LAVV, using a mattress suture, creating a double valvular patch parallel to the valvular plane; (C) the free edge of the LAVV sutured to the plicated patch component; (D) the right atrioventricular is attached in the same line with the LAVV. LAVV, left atrioventricular valve; RAVV, right atrioventricular valve.

after repairing the LAVV. The pericardial patch is sutured around the atrial defect, staying initially inferior and lateral to the lateral edge of the coronary sinus and the back medially just below the anterior lip of the coronary sinus avoiding the injury of the conduction system. The coronary sinus is left to drain physiologically into the right atrium. The cleft in the LAVV is approximated with interrupted suture in each patient. If the LAVV insufficiency is present, single $U$ stitches reinforced with pledget or LAVV annuloplasty might be employed. At the end of any conservative procedure the LAVV annulus should be sized with appropriate Hegar obturators.

\section{The management of the RVOT}

The main pulmonary artery should be opened. The pulmonary valve should be carefully explored and valvotomy done if necessary. The size of the pulmonary annulus is determined by use of a Hegar dilator. RVOT should be explored from the right atrium as well as the main pulmonary artery and the right infundibular incision in cases undergoing right ventriculotomy. Excessive resection of the hypertrophied right ventricle bundles should be performed to enlarge the RVOT. When the pulmonary valve is more than $1-2 \mathrm{~mm}$ smaller than the standard estimated size, a transannular repair should be performed. When the pulmonary valve is adequate but infundibular stenosis is severe, or in cases when the exposure of the subaortic region is poor, a separate infundibular incision should be performed.

In our experience, we treated 25 patients with CAVSDTOF underwent complete repair. Twelve patients underwent previous palliation. Complete repair was possible in all patients. Three (12\%) hospital deaths occurred in this series. During the same hospitalization, one patient required reoperation and 2 other patients required reoperating during the follow-up due to LAVV and pulmonary valve insufficiency. At follow-up, the mean gradient across the 
Table 1 Summary of published series in patients with complete atrioventricular septal defect and tetralogy of Fallot or double outlet right ventricle

\begin{tabular}{|c|c|c|c|c|}
\hline Author & Years & $\begin{array}{c}\text { No. of } \\
\text { patients }\end{array}$ & Technique & Mortality \\
\hline 1. d'Allaines et al. & 1968 & 2 & One-patch & $1(50 \%)$ \\
\hline 2. Fisher et al. & 1975 & 2 & One-patch & $1(50 \%)$ \\
\hline 3. Zavanella et al. & 1977 & 1 & Two-patch & 0 \\
\hline 4. Berger et al. & 1978 & 5 & One-patch & $3(60 \%)$ \\
\hline 5. Pacifico et al. & 1980 & 5 & Both & $2(40 \%)$ \\
\hline 6. Binet et al. & 1980 & 3 & Both & 0 \\
\hline 7. Arciniegas et al. & 1981 & 4 & One-patch & 0 \\
\hline 8. Yakirevich et al. & 1983 & 1 & Two-patch & 0 \\
\hline 9. Uretzky et al. & 1984 & 14 & One-patch & $5(36 \%)$ \\
\hline 10. Ueda et al. & 1984 & 2 & $?$ & 0 \\
\hline 11. Sade et al. & 1985 & 1 & $?$ & 0 \\
\hline 12. Mack et al. & 1985 & 1 & $?$ & 0 \\
\hline 13. Vargas et al. & 1986 & 13 & One-patch & $3(23 \%)$ \\
\hline 14. LeBlanc et al. & 1986 & 11 & Both & 2 (18.2\%) \\
\hline 15. Pacifico et al. & 1988 & 12 & Two-patch & $1(8 \%)$ \\
\hline 16. Vogel et al. & 1989 & 5 & $?$ & $2(40 \%)$ \\
\hline 17. da Silva et al. & 1989 & 6 & $?$ & 0 \\
\hline 18. Alonso et al. & 1990 & 9 & Two-patch & 0 \\
\hline 19. Ilbawi et al. & 1990 & 9 & Two-patch & $1(11 \%)$ \\
\hline 20. Agarwal et al. & 1991 & 1 & Two-patch & 0 \\
\hline 21. Gatzoulis et al. & 1994 & 10 & Two-patch & $1(10 \%)$ \\
\hline 22. Chiu et al. & 1995 & 5 & Two-patch & $1(20 \%)$ \\
\hline 23. Redmond et al. & 1996 & 6 & Both & 0 \\
\hline 24. Bertolini et al. & 1996 & 12 & Two-patch & $5(42 \%)$ \\
\hline 25. Karl et al. & 1997 & 26 & $?$ & 1 (3.9\%) \\
\hline 26. Delius et al. & 1997 & 29 & Two-patch & $3(10 \%)$ \\
\hline 27. Najm et al. & 1998 & 31 & Both & $2(6.5 \%)$ \\
\hline 28. O'Blenes et al. & 1998 & 11 & Two-patch & $1(9 \%)$ \\
\hline 29. McElhinney et al. & 1998 & 9 & One-patch in 8 & 0 \\
\hline 30. Tlaskal et al. & 1998 & 14 & Two-patch & $1(7.1 \%)$ \\
\hline 31. Okada et al. & 1999 & 9 & Two-patch & $1(11 \%)$ \\
\hline 32. Reddy et al. & 1998 & 6 & One-patch & 0 \\
\hline 33. Suzuki et al. & 1998 & 13 & Two-patch & 2 \\
\hline 34. Parvathy et al. & 2000 & 3 & $?$ & 0 \\
\hline 35. Schmidt et al. & 2000 & 9 & Two-patch & 0 \\
\hline 36. Mei et al. & 2000 & 6 & Two-patch & $1(16.7 \%)$ \\
\hline 37. Fraser et al. & 2001 & 13 & Two-patch & 0 \\
\hline 38. Oshima et al. & 2001 & 10 & Two-patch & $3(30 \%)$ \\
\hline
\end{tabular}

Table 1 (continued)
Table 1 (continued)

\begin{tabular}{lllll}
\hline Author & Years & $\begin{array}{c}\text { No. of } \\
\text { patients }\end{array}$ & Technique & Mortality \\
\hline 39. Prifti et al. & 2004 & 17 & One-patch & $3(17.6 \%)$ \\
40. Ricci et al. & 2008 & 8 & Two-patch & 0 \\
41. Sarioglu et al. & 2008 & 7 & Two-patch & 0 \\
42. Hoohenkerk et al. 2008 & 20 & Two-patch & 0 \\
43. Brancaccio et al. & 2009 & 33 & Both & 0 \\
44. Shuhaiber et al. & 2012 & 61 & Both & $4(6.6 \%)$ \\
45. Gupta et al. & 2014 & 13 & Two-patch & 0 \\
46. Hu et al. & 2014 & 17 & Two-patch & $1(6 \%)$ \\
47. Morimoto et al. & 2014 & 10 & Two-patch & 0 \\
48. Talwar et al. & 2015 & 1 & Two-patch & 0 \\
49. Pavy et al. & 2016 & 1 & One-patch & 0 \\
50. Vitanova et al. & 2016 & 47 & Two-patch & $2(4 \%)$ \\
Total & & 564 & & $53(9.4 \%)$ \\
\hline
\end{tabular}

RVOT was $17 \pm 6 \mathrm{mmHg}$ and the LAVV regurgitation grade $1.4 \pm 0.6$, significantly lower than postoperatively.

The first article reporting successful correction for this malformation was by d'Allaines et al. in 1969 (2). Since then, there have been 50 separate reports of complete surgical repair of CAVSD-TOF in 564 patients (Table 1). Most of the initial reports presented those cases undergoing successful correction, instead the failure to repair or deaths are not reported. Despite consistent series with CAVSD have been reported so far, the specific association of CAVSD-TOF remains still a topic of further investigation. The overall mortality reported in 50 studies was 53 patients (9.4\%). In the collected series of patients with CAVSDTOF, the postoperative mortality after complete correction reduced significantly during the last decade. Such improvement can be attributed to several factors, including better diagnostic accuracy, perioperative care, surgical approach and a learning curve with this malformation. There are several factors that are thought to contribute to morbidity and mortality after repair of CAVSD-TOF. These include LAVV regurgitation, residual shunts, RVOTO, and the optimal surgical approach should be designed to minimize the occurrence of these problems.

Total correction in children with CAVSD-TOF is challenging for the surgeons, due to the rare incidence, anatomic characteristics, age at presentation, and surgical strategies. Performing primary repair of CAVSD-TOF when the patient is older has potential advantages, 
such as enabling the use larger valvular conduits to relieve the RVOTO, better tolerance of transannular patch enlargement, and easier atrioventricular valve reconstruction (14). The repair of TOF often results in pulmonary valve insufficiency or residual stenosis. The resulting volume overload or right ventricular hypertension can potentially worsen the right atrioventricular valve (RAVV) regurgitation and impact significantly on short and long-term outcome. Significant regurgitation of the LAVV can elevate the pulmonary artery pressure and increase the pulmonary valve insufficiency, particularly if a transannular patch is present. These factors in combination with technical challenges result in a greater risk for repair of CAVSD-TOF than the risk for either lesion alone (19).

Most children with CAVSD-TOF have symptoms beyond the neonatal or even the infant period (1). As in cases with TOF, the age at clinical presentation depends on the degree of the RVOTO. Such obstruction, effectively serves as a pulmonary artery band, protecting the pulmonary vasculature from the high pulmonary blood flow characteristic of CAVSD, thereby allowing repair at an older age. Severe cyanosis in the neonatal period indicates severe RVOTO. Heart failure during the neonatal period, although rare, has the indication for a complete repair. Initially, in our experience, the children with CAVSDTOF underwent palliation as a first choice procedure, and later on a complete repair. The arguments for palliation and delayed repair include an easier atrioventricular valve's reconstruction and placement of a larger valved conduit if needed (14). However, palliation carries potential complications, including prolonged cyanosis, excessive ventricular hypertrophy, volume loading of the ventricle, and progression of the atrioventricular valves' regurgitation. With growing experience, we have employed a modified Blalock-Taussig shunt only in patients with small pulmonary arteries or in cyanotic neonates followed by a definitive repair after 6 months of life as the atrioventricular valve tissue is somewhat stronger. In other cases we prefer to undergo primary complete repair, possibly after the first 6 months of life. The postoperative mortality and morbidity in patients undergoing palliation prior complete repair is similar with patients undergoing primary repair.

A careful preoperative evaluation is required. The presence of a well-developed right ventricle is an important preoperative prerequisite for undergoing definitive biventricular repair. A possible cause of postoperative right ventricular failure might be the small ventricular cavity. These children should be considered for a univentricular repair (Fontan procedure) or possibly a one and a half ventricular repair (CAVSD-TOF repair plus bidirectional Glenn shunt). Doppler echocardiography is a perfect diagnostic tool in delineating cardiac morphology and physiology in the hand of an experienced echocardiographist. However, the cardiac catheterization remains the procedure of choice in cases with a coronary artery crossing the RVOT.

The association of CAVSD with TOF is a unique anatomic situation that must be considered carefully when planning the surgical correction. The VSD morphology is similar to that of CAVSD except that the anterior superior border extends far anteriorly, presenting as a subaortic extension, caused by the unwedging of the aorta seen in CAVSD. The aortic valve sits anterior to and above the base of the anterior bridging leaflet (20), resulting in a long left ventricular outflow tract. The unwedging of the aorta exaggerates the anterior extension of the VSD and the transatrial view of such extension is obscured by the location of the superior bridging leaflet. Suzuki et al. (21) indicate that the aorta is dextraposed in all patients with CAVSD Rastelli type C; however, when TOF is associated the aorta is dextraposed to an even greater degree, so that the majority overrode the septum for more than $50 \%$, making it a double outlet right ventricle. The Rastelli type $\mathrm{C}$ configuration is frequently found with in CAVSDTOF. In this type the anterior bridging leaflet extends far into the right ventricle. The anterior bridging leaflet is mainly presented as a "free-floating" meaning unattached to the ventricular septal crest. However, recent anatomic studies, demonstrated that in some cases with Rastelli type $\mathrm{C}$, single thick chordae anchoring the anterior bridging leaflet to the ventricular septal crest, without impeding the interventricular communication were present. When a freefloating bridging leaflet is present and the surgeon prefers the one-patch technique, maximal tissue preservation for the LAVV reconstruction is possible by making the incision in the bridging leaflets along the right aspect of the crest. In cases when the anterior bridging leaflet is anchored to the ventricular septal crest, the surgeon should decide if the chordae need to be cut or not, to preserve as much valvular tissue for the LAVV. According to our experience, the deficiency of valvular tissue, such as in neonates, double orifice LAVV or dysplastic valvular tissue, predisposes a reduction of the mobile valve area due to incorporation of leaflet tissue in the suture line which are placed under tension. This induces a high incidence of suture dehiscence and as consequence, important postoperative 
LAVV regurgitation. One of the solutions might be the augmentation of the leaflet tissue as proposed in our technique. This modification provides additional tissue for reconstructing appropriately the LAVV in cases with leaflet tissue deficiency, promotes leftward displacement, improved coaptation and tension-free closure of the cleft.

In the Rastelli $\mathrm{C}$ configuration, during systole the superior leaflet of the common atrioventricular valve is pushed toward the atrium and the outflow tract opens widely before correction. The inserted ventricular patch, which constitutes the right-hand wall of the left ventricular outflow tract, may create a narrow outflow tract and consequently obstruction when the patch is too small anteriorly. Two important considerations should be made. Firstly, the division of the bridging leaflet and the closure of the subaortic component of the VSD as much rightward as possible, not only would preserve maximal tissue for the LAVV reconstruction, but also, creates a larger outflow tract. Secondly, the patch should be fairly patulous up in the superior aspect of the VSD and enlarged anteriorly. This will increase the subaortic space, avoiding the left ventricular outflow tract obstruction. The employment of a Hegar sizer through the aortic valve is a certain procedure to avoid iatrogenic left ventricular outflow tract obstruction.

We have employed the one-patch, modified one-patch and two-patch techniques for CAVSD-TOF. Different recent studies have reported a re-operation rate between $6.8 \%$ and $11 \%$ in patients with CAVSD undergoing twopatch or single patch technique correction (22). Other reported CAVSD series including both techniques failed to demonstrate statistically the single-patch technique as a possible predictor for early and late re-operation $(1,22)$. Dividing the anterior bridging leaflet, affords an improved view of the margins of the defect, identifying carefully the true extent of the VSD through the atrium. To improve the exposure of the VSD,, we employed four averting pledget stitches placed at each of the newly created atrioventricular valves' leaflets. This maneuver permits to identify better the anterior extension of the VSD. We prefer to close the VSD through a transatrial approach. We feel this approach prevents residual VSD and subaortic obstruction. In case when the two-patch technique is employed without dividing the anterior bridging leaflet, an extended right ventriculotomy is obligatory for closure of the anterior extension of the VSD (23). However, in patients necessitating a right ventriculotomy for outflow tract reconstruction, the anterior extension of the VSD was closed from the right side. We believe that the best surgical management should be individualized for each patient, however, when possible, we try to not perform a right ventriculotomy.

The appropriate management of the RVOT remains a topic of controversy. A right ventricular incision greatly enhances the exposure of the anterior extension of the VSD and the hypertrophied right ventricular muscle bundles can be easier resected than a transatrial-transpulmonary approach. The potential drawbacks of a right ventriculotomy include postoperative ventricular dysfunction, late dysrhythmias and if the incision is transannular, pulmonary valve insufficiency. The rate of dysrhythmias may relate primarily to right ventricular dysfunction and dilatation, which is progressive with time in the face of pulmonary valve insufficiency (24). The transatrialtranspulmonary approach, as advocated by Karl (25) allows closure of the VSD and relief of the RVOTO in isolated TOF without the need for a right ventriculotomy. The RVOTO in CAVSD-TOF should be relieved by employing a right ventriculotomy and RVOT patch enlargement, or when a small pulmonary valve is present, a transannular approach. Some authors have advocated the avoidance of a transannular incision preferring a valve conduit over a transannular patch (25) others have not found a transannular patch to be detrimental to short or long-term results (19). If a transannular patch is employed a complete relief of RVOTO would appear to be essential (13). However, as in patients with simple TOF, right ventricular dilatation due to pulmonary valve insufficiency may develop in patients with a transannular patch, requiring pulmonary valve replacement with a valved homograft. In our experience, the employment of a pulmonary homograft as a first choice has been reserved for patients with acquired pulmonary valve atresia or with a coronary artery crossing the RVOT.

We may conclude that patients with associated CAVSD to TOF are at a higher risk than the general CAVSD population, however complete repair seems to offer acceptable early and mid-term outcome in terms of mortality and reoperation rate. Palliation prior complete repair may be reserved in specific cases presenting small pulmonary arteries or severely cyanotic neonates. The preservation of the LAVV competency is an important factor affecting the postoperative functional status, reoperation rate and mortality. The RVOT should be managed in the same fashion as for isolated TOF, however, a transatrial-transpulmonary approach should be taken into consideration as the best choice. 


\section{Acknowledgements}

None.

\section{Footnote}

Conflicts of Interest: The author has no conflicts of interest to declare.

\section{References}

1. Najm HK, Van Arsdell GS, Watzka S, et al. Primary repair is superior to initial palliation in children with atrioventricular septal defect and tetralogy of Fallot. J Thorac Cardiovasc Surg 1998;116:905-13.

2. d'Allaines C, Colvez P, Fevre C, et al. A rare congenital cardiopathy: association of tetralogy with complete atrioventricular communication. Clinical detection and surgical repair. Arch Mal Coeur Vaiss 1969;62:996-1013.

3. Pacifico AD, Kirklin JW, Bargeron LM Jr. Repair of complete atrioventricular canal associated with tetralogy of Fallot or double-outlet right ventricle: report of 10 patients. Ann Thorac Surg 1980;29:351-6.

4. LeBlanc JG, Williams WG, Freedom RM, et al. Results of total correction in complete atrioventricular septal defects with congenital or surgically induced right ventricular outflow tract obstruction. Ann Thorac Surg 1986;41:387-91.

5. Hu R, Zhang H, Xu Z, et al. Surgical management of complete atrioventricular septal defect with tetralogy of fallot. Ann Thorac Cardiovasc Surg 2014;20:341-6.

6. Hoohenkerk GJ, Schoof PH, Bruggemans EF, et al. 28 years' experience with transatrial-transpulmonary repair of atrioventricular septal defect with tetralogy of Fallot. Ann Thorac Surg 2008;85:1686-9.

7. Ricci M, Tchervenkov CI, Jacobs JP, et al. Surgical correction for patients with tetralogy of Fallot and common atrioventricular junction. Cardiol Young 2008;18 Suppl 3:29-38.

8. Sarioğlu T, Erek E, Yalçinbaş YK, et al. Combination of complete atrioventricular septal defect and tetralogy of Fallot: surgical management and its results. Turk Kardiyol Dern Ars 2008;36:461-6.

9. Raju V, Burkhart HM, Rigelman Hedberg N, et al. Surgical strategy for atrioventricular septal defect and tetralogy of Fallot or double-outlet right ventricle. Ann Thorac Surg 2013;95:2079-84; discussion 2084-5.

10. Shuhaiber JH, Robinson B, Gauvreau K, et al. Outcome after repair of atrioventricular septal defect with tetralogy of Fallot. J Thorac Cardiovasc Surg 2012;143:338-43.

11. Gupta U, Polimenakos AC, El-Zein C, et al. Tetralogy of Fallot with atrioventricular septal defect: surgical strategies for repair and midterm outcome of pulmonary valvesparing approach. Pediatr Cardiol 2013;34:861-71.

12. Morimoto K, Hoashi T, Kagisaki K, et al. Post-operative left atrioventricular valve function after the staged repair of complete atrioventricular septal defect with tetralogy of Fallot. Gen Thorac Cardiovasc Surg 2014;62:602-7.

13. Brancaccio G, Michielon G, Filippelli S, et al.

Transannular patching is a valid alternative for tetralogy of Fallot and complete atrioventricular septal defect repair. J Thorac Cardiovasc Surg 2009;137:919-23.

14. Vitanova K, Cleuziou J, Schreiber C, et al. Long-Term Outcome of Patients With Complete Atrioventricular Septal Defect Combined With the Tetralogy of Fallot: Staged Repair Is Not Inferior to Primary Repair. Ann Thorac Surg 2016. [Epub ahead of print].

15. Prifti E, Crucean A, Bonacchi M, et al. Total correction of complete atrioventricular septal defect with tetralogy of Fallot. J Heart Valve Dis 2003;12:640-8.

16. Prifti E, Bonacchi M, Bernabei $M$, et al. Repair of complete atrioventricular septal defect with tetralogy of fallot: our experience and literature review. J Card Surg 2004;19:175-83.

17. Prifti E, Bonacchi M, Bernabei M, et al. Repair of complete atrioventricular septal defects in patients weighing less than 5 kg. Ann Thorac Surg 2004;77:1717-26.

18. Prifti E, Bonacchi $M$, Leacche $M$, et al. A modified 'single patch' technique for complete atrioventricular septal defect correction. Eur J Cardiothorac Surg 2002;22:151-3.

19. Vargas FJ, Coto EO, Mayer JE Jr, et al. Complete atrioventricular canal and tetralogy of Fallot: surgical considerations. Ann Thorac Surg 1986;42:258-63.

20. Ebels T, Ho SY, Anderson RH, et al. The surgical anatomy of the left ventricular outflow tract in atrioventricular septal defect. Ann Thorac Surg 1986;41:483-8.

21. Suzuki K, Ho SY, Anderson RH, et al. Morphometric analysis of atrioventricular septal defect with common valve orifice. J Am Coll Cardiol 1998;31:217-23.

22. Prifti E, Bonacchi M, Baboci A, et al. Surgical outcome of reoperation due to left atrioventricular valve regurgitation after previous correction of complete atrioventricular septal defect. J Card Surg 2013;28:756-63.

23. O'Blenes SB, Ross DB, Nanton MA, et al. Atrioventricular septal defect with tetralogy of Fallot: results of surgical correction. Ann Thorac Surg 1998;66:2078-82; discussion 
2082-4.

24. Gatzoulis MA, Till JA, Somerville J, et al. Mechanoelectrical interaction in tetralogy of Fallot. QRS prolongation relates to right ventricular size and predicts malignant ventricular arrhythmias and sudden death.

Cite this article as: Prifti E. Repair of complete atrioventricular septal defect with tetralogy of Fallot. Transl Pediatr 2017;6(1):17. doi: 10.21037/tp.2017.01.01
Circulation 1995;92:231-7.

25. Karl TR. Atrioventricular septal defect with tetralogy of Fallot or double-outlet right ventricle: surgical considerations. Semin Thorac Cardiovasc Surg 1997;9:26-34. 